\title{
Urban ecological energy generation on the example of elevation wind turbines located at Center of Energy AGH
}

\author{
Mariusz Filipowicz ${ }^{1,}$, Maciej Żołądek ${ }^{1}$, Wojciech Goryl ${ }^{1}$, and Krzysztof Sornek $^{1}$ \\ ${ }^{1}$ AGH University, Faculty of Energy and Fuels, Department of Sustainable Energy Development, \\ Mickiewicza Av. 30, 30-059 Krakow, Poland
}

\begin{abstract}
Nowadays, the worldwide growing demand for energy from renewable sources is observed. This fact is related to a number of factors, especially environmental ones. In the renewable energy sector, the most dynamic development which can be seen is wind energy. This is due to the construction of huge wind turbines, whose power exceeds even a few megawatts. The main problem that should be solved is finding a proper location for such turbines. Generally, wind turbines are located off-shore and on-shore. The most favourable are off-shore due to better wind condition, which relates to power generation. Notwithstanding, it is possible to install smaller turbines in urban areas: so-called wind turbines in built-up areas or integrate wind turbines with buildings (BIWT). This creates an opportunity to develop an integrated system of small energy sources located directly in cities. However, it is necessary to be aware of the many problems connected with the above mentioned installations. The article presents an overview and data related to operation of wind turbines integrated with the Center of Energy AGH building.
\end{abstract}

\section{Introduction}

Buildings consume most of the energy produced in the world. An architectural trend replacing energy-consuming buildings with zero energy ones has appeared. An example of such a solution are buildings with integrated wind turbines. Their effectiveness depends on many factors. Especially CFD analyses carried out in [1] allowed the determination that the appropriate roof structure on which the wind turbine will be located may allow increasing power density by up to $86 \%$. The paper [2] proves that wind turbine installations connected with buildings may satisfy up to $20 \%$ of its energy demand.

In [3] it has been shown, that horizontal axis wind turbines have a higher performance in flat terrain applications. The main advantage of those turbines is their efficiency, but their disadvantage is that they only operate under unidirectional wind conditions, so its utility is limited in urban environments. Vertical axis wind turbines are more suitable in built-up areas because of accommodating to multidirectional and turbulent conditions. Flat roofs are more desirable to install wind turbines due to the lack of effect of wind velocity decrease. There are three basic types of turbines which are located in built-up areas $[4,5]$ :

\footnotetext{
* Corresponding author: mariusz.filipowicz@agh.edu.pl
} 
- Building integrated wind turbines (BIWT) - attached to the building,

- Building mounted wind turbines (BMWT) - connected to the structure of the building. In most cases turbines are mounted on the buildings' roof,

- Building augmented wind turbines (BAWT) - building is purposely used to strengthen wind flow through the turbine. Effect is achieved by special building construction acting as a flow concentrator.

In order to strengthen the wind flows near the buildings, mounting wind turbines in a special way is required. There are many factors which affect wind flow. The geometry of buildings, their height, width, location, construction etc. have to be analysed. Channelling of wind flow, terrain roughness, turbulence or wind blasts are the most important factors. Meteorological data collecting for a minimum 10 years is required to carry out such an analysis [6]. An interesting concept to achieve strengthened wind flow is the formation of building façade elements. The solutions described in [7, 8] illustrate advanced technologies of wind energy resources exploitation for urban environment. For example, use of dedicated guide vanes connected with small wind turbines allows one to multiply power generation due to redirection of wind flow.

For turbines placed near the edge of the roof, special attention on the variable direction of air flow is indispensable [2]. Such turbines need a special shape of the blades. It is also important to ensure that the installed turbine is not located in a turbulent zone caused by surrounding obstacles.

An economical analysis made in [9] shows the potential of mounting small wind turbines under different urban location settings. Small wind turbines in Germany could be economically feasible in exposed areas with an average wind speed higher than $4.5 \mathrm{~m} / \mathrm{s}$. Inclusion of an energy storage system increases the NPV of small wind turbines investments in most cases.

\section{Description of wind turbines installation}

The paper analyses the operation of the BIWT installation located on the façade of the Center of Energy AGH building. Two different turbines - a horizontal axis wind turbine (HAWT) and a vertical axis wind turbine (VAWT) are installed. Location of the turbines is shown in Figure 1. The basic parameters of the described turbines are shown in Table 1.

Wind turbines are placed in designed technological holes on the façade of the CE AGH building. This building is located on Czarnowiejska Street in Krakow. The turbines are oriented in the north-west direction (Figure 2), which means that the installation works optimally when wind blows from that direction.

Table 1. The basic parameters of the wind turbines installed on the facade of the Center of Energy AGH building.

\begin{tabular}{|l|c|c|}
\hline \multirow{2}{*}{\multicolumn{1}{|c|}{ Type }} & HAWT & VAWT \\
\cline { 2 - 3 } & $\begin{array}{c}\text { Ventus Energia, Swind } \\
\text { New 1500 }\end{array}$ & Hipar, Ecorote 600 \\
\hline Start-up wind speed $[\mathrm{m} / \mathrm{s}]$ & 2.3 & 1.2 \\
\hline Power $[\mathrm{kW}]$ & 1.5 & 0.65 \\
\hline Nominal wind speed $[\mathrm{m} / \mathrm{s}]$ & 10 & 12 \\
\hline Wind speed of break on $[\mathrm{m} / \mathrm{s}]$ & - & 25 \\
\hline Size $[\mathrm{m}]$ & Diameter $2.2 \mathrm{~m}$ & $\begin{array}{c}\text { Diameter } 1.0 \mathrm{~m} \\
\text { High } 1.5 \mathrm{~m}\end{array}$ \\
\hline Changing blade angle & Yes, in rage of $+/-40$ degree & No \\
\hline $\begin{array}{l}\text { Changing the position of the } \\
\text { turbine nacelle }\end{array}$ & Yes, in rage of $+/-10$ degree & - \\
\hline Number of blades & 3 & 4 \\
\hline
\end{tabular}




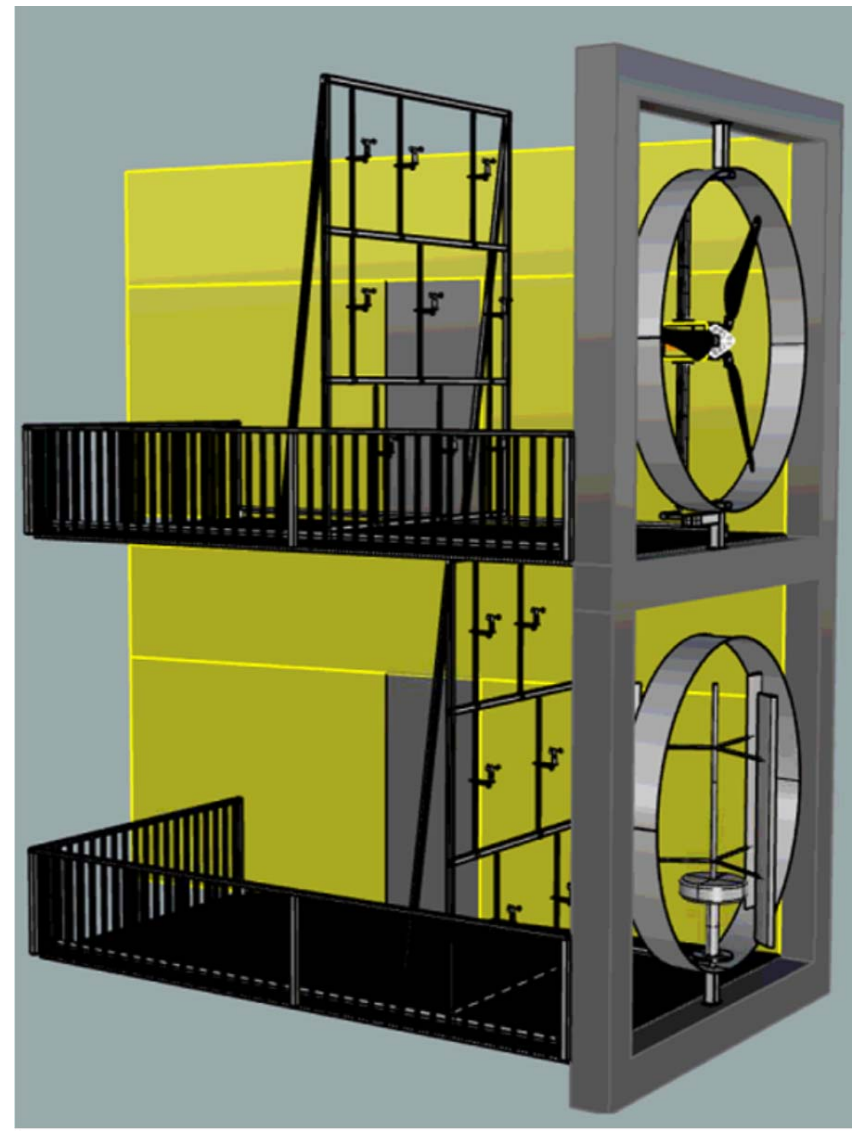

Fig. 1. Turbines configuration on the facade of the Center of Energy building (at the top horizontal axis wind turbine, at the bottom vertical axis wind turbine).

\section{Top view}

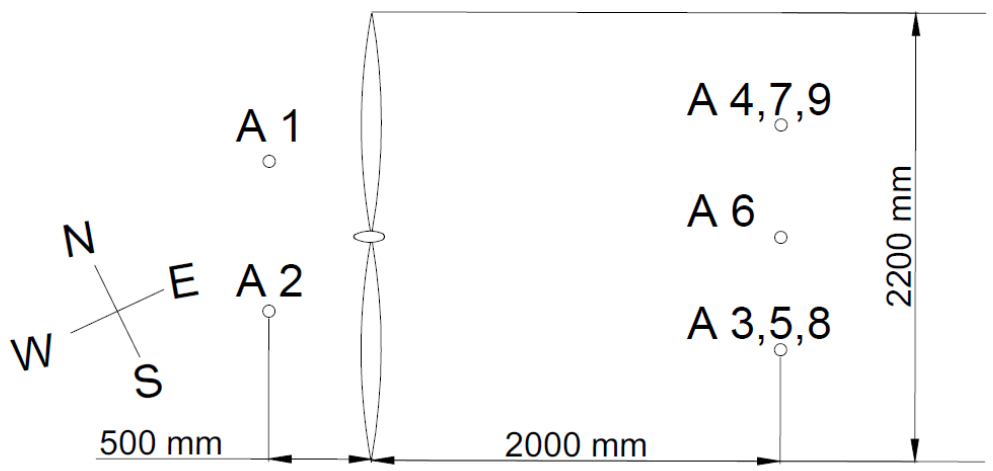

Fig. 2. Schematic diagram of anemometers location in front of and behind the turbine, A1-A9 shows anemometers.

The horizontal axis wind turbine is placed at the top level. This turbine is equipped with an electromagnetic clutch that activates or disconnects the power generator at predetermined turbine speeds. The vertical axis wind turbine is placed at the bottom level. 
Besides the turbines, the installation is equipped with number of additional components. The main element is a dedicated automation system that monitors the operation of both turbines and collects all the operational parameters. Included with this is a meteorological station that delivers information about air temperature and humidity, wind speed and its direction. In front of each turbine, two anemometers measuring the speed of wind blowing into the turbine are installed. In addition, a sliding sensor array consisting of seven anemometers is located behind each turbine (Figure 2).

The anemometers allow determining the amount of wind energy used by a given turbine. The turbines installation is equipped with breaks, tachometers, vibration sensors, torque sensors and sound sensors. Therefore, this installation differs from typical wind turbine installations due to the expanded data acquisition system and the auxiliary components. Installation can deliver electricity into the power grid or store energy in the storage system. Moreover, the generator can be connected to the electronic load allowing for controlling power output from the turbines.

\section{Results}

The following measurements were performed: analysis of wind resources, power generation and influence of the wind turbines to the building and surrounding area.

\subsection{Examination of wind resources}

The period of October and November last year were analysed, see figure 3. This figure shows data registered by the A1 anemometer (inlet wind). For October all data are presented and compared to data for Ksavery orkan. Also, wind velocity histograms for specific cases as huge vibration occurrence (higher than $2 \mathrm{~mm} / \mathrm{s}$ ), heavy noise (over $70 \mathrm{~dB}$ ) and relatively large rotations (more than $100 \mathrm{rpm}$ ) are presented.

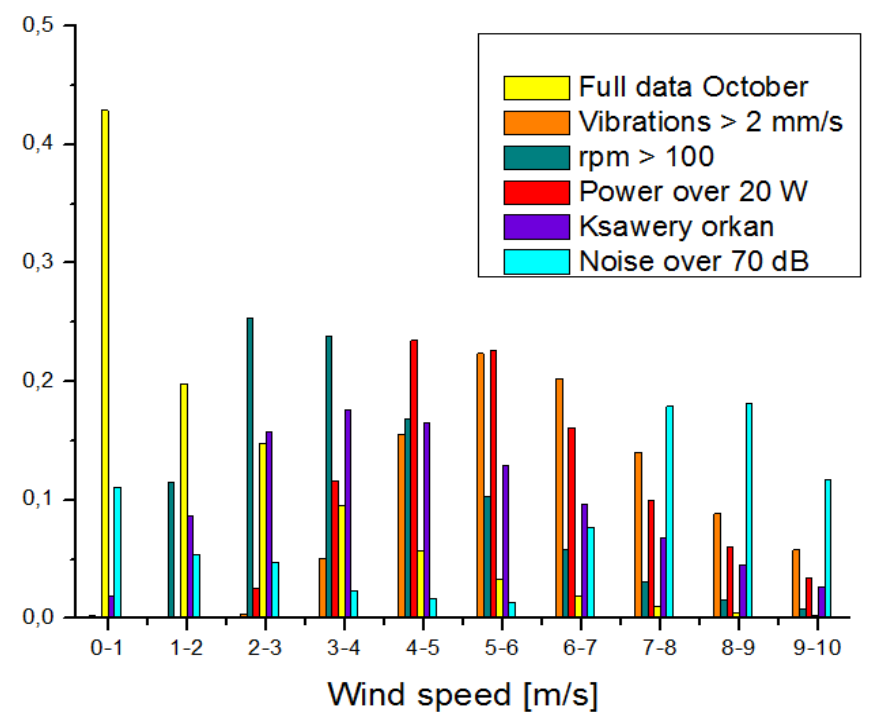

Fig. 3. Histograms of inlet wind velocities in October 2017 for selected cases. Data are registered by A1 anemometer.

In figure 3, it is visible that generally wind speed is low in the turbine area, most of the observed velocities (over $40 \%$ ) are below $1 \mathrm{~m} / \mathrm{s}$. The velocities in the range of $1-4 \mathrm{~m} / \mathrm{s}$ 
consist of ca. $45 \%$ and velocities greater than $5 \mathrm{~m} / \mathrm{s}$ consist of only $10-12 \%$ off all velocities. It shows that wind conditions are rather poor. Comparing to analogous data for the Ksavery orkan, it is visible that e.g. velocities larger than $5 \mathrm{~m} / \mathrm{s}$ consist of ca. $50 \%$ off all velocities. Analysing the behaviour of the turbine, it can be noticed that: large vibrations start to appear for winds faster than $3 \mathrm{~m} / \mathrm{s}$ and are predominant for velocities in range 4-7 m/s, and decreased for velocities larger than $7 \mathrm{~m} / \mathrm{s}$. It illustrates the resonance character of vibration generation. The heavy noise appears for velocities larger than $6 \mathrm{~m} / \mathrm{s}$.

Figure 4 shows analogous data for outlet wind (A3 anemometer).

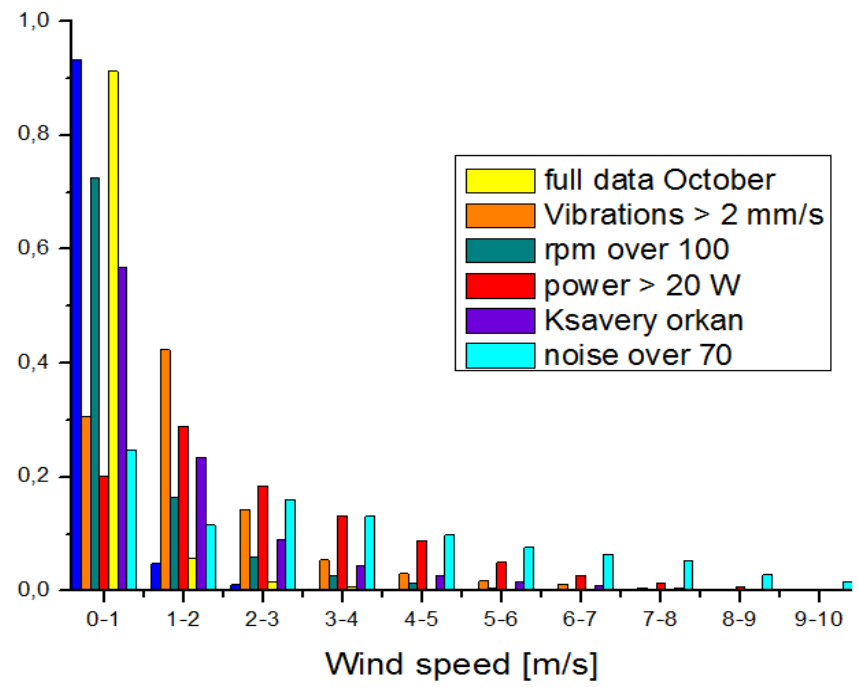

Fig. 4. Histograms of outlet wind velocities in October 2017 for selected cases. Data measured by A3 anemometer.

Comparing Figures 3 and 4, it is visible that generally, outlet wind velocities are smaller (due to attenuation by the wind turbine). The larger rotations occur for velocities smaller than $1 \mathrm{~m} / \mathrm{s}$, which indicates the efficiency of the harvesting and transformation of kinetic wind energy by the turbine. The other parameters behave in a similar way.

The action of wind turbine dependent of wind velocity is presented in figure 5 .

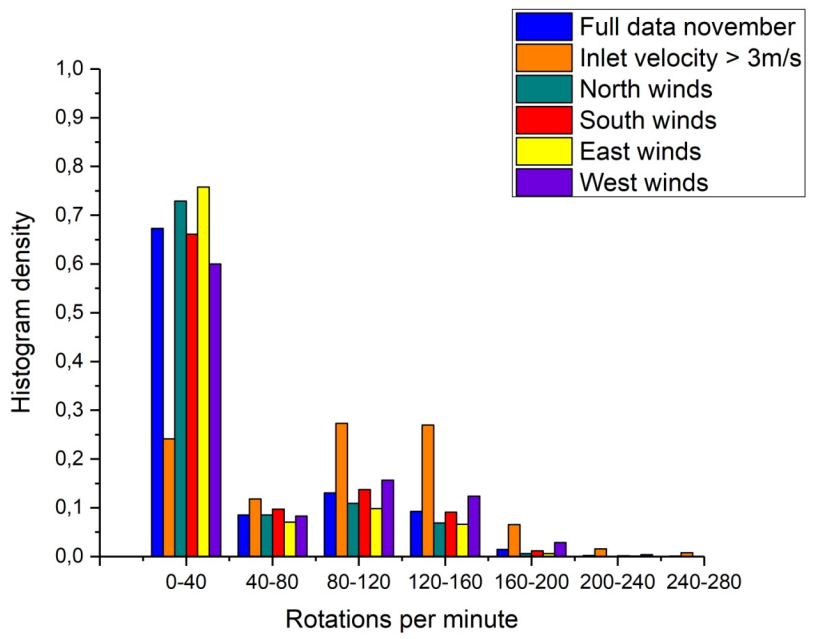

Fig. 5. Histogram of rotation velocity for varied wind directions. 
Low rotational speed is mainly induced by east winds and for higher rotational velocities west winds are more responsible. However, in the presented locations low rotations mostly occur.

\subsection{Power generation}

The power generated by the turbine for inlet winds larger than $3 \mathrm{~m} / \mathrm{s}$ in function of rotational speed is presented in figure 6 .

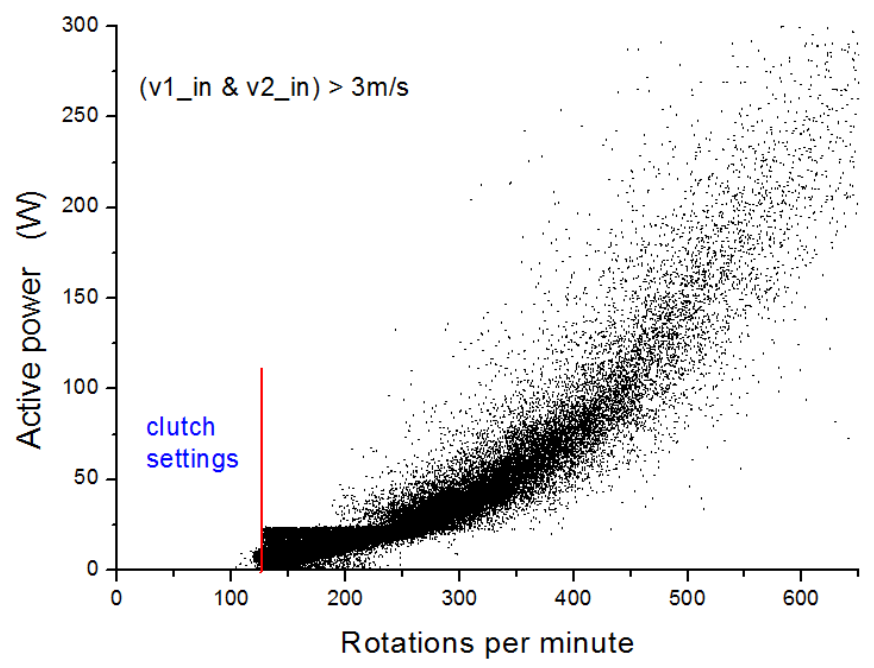

Fig. 6. Plot generated power - rotational speed for inlet winds velocities larger than $3 \mathrm{~m} / \mathrm{s}$.

Based on this data, nonlinear dependence can be observed. It may be the result of a strong variation of wind directions not allowing the transfer of energy from the turbine with the same efficiency. The lack of power generation for a rotational speed lower than $120 \mathrm{rpm}$ is a result of the clutch setting (the clutch switches on at $120 \mathrm{rpm}$ ).

\subsection{Influence of the wind turbines}

The generated noise is presented in Figure 7.

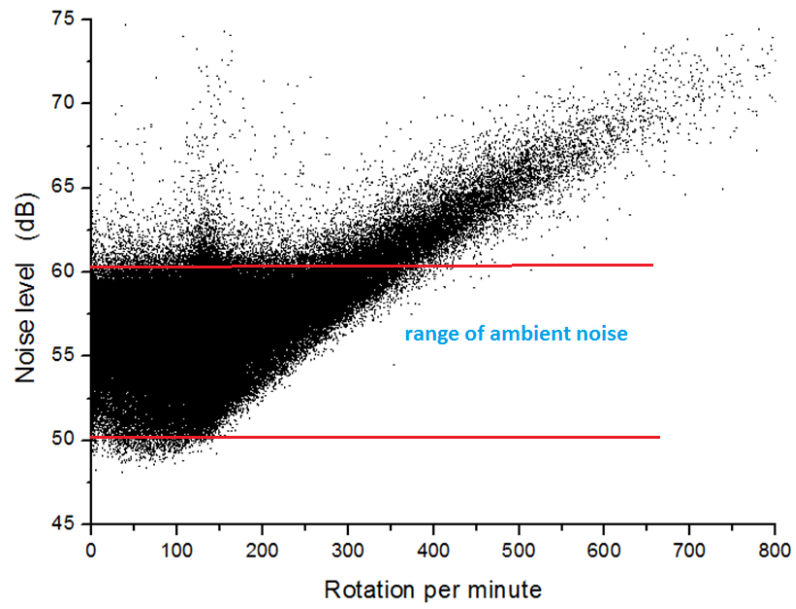

Fig. 7. Level of registered noise (generated by the turbine and coming from ambient). 
Ambient background noise is in the range of ca. 50-60 dB (difference during nights and days coming from busy street and from the building facilities, e.g. exhaust fans etc.). The extra noise is visible for a rotational speed higher than ca. $300 \mathrm{rpm}$. Heavy noise (ca. $70 \mathrm{db}$ ) for a high rotational speed more than $600 \mathrm{rpm}$ is observed. It is self-evident that a curved dependence can be noticed due to strong wind generating noise itself. The noise sensor is placed about 20 meters above street level and near the turbine blades.

In aim to illustrate origin of vibrations, the correlation vibrations-rotations were constructed and are presented in figure 8 .

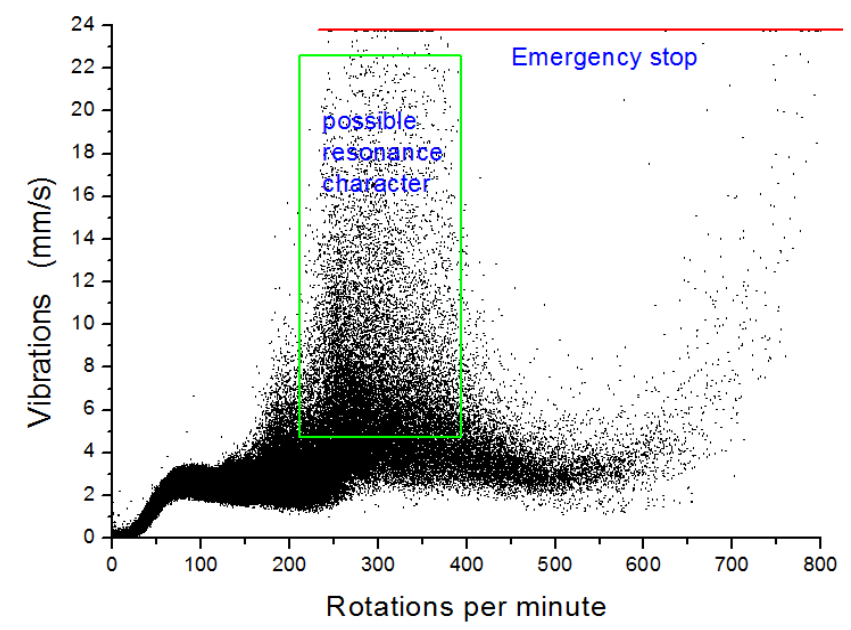

Fig. 8. Correlation of vibrations and the turbine rotational speed.

The strongest vibrations appear for rotational speeds near $300 \mathrm{rpm}$. It shows that the resonance mechanism is responsible for its enhancement. The relatively weak vibrations occur for turbine rotational speeds in the range of 450-600 rpm and increasing for rotational speeds higher than $700 \mathrm{rpm}$, but that is a rare situation. The turbine vibration emergency stop was set on $24 \mathrm{~mm} / \mathrm{s}$ and its operation is visible in figure 8 .

Data presented in figure 9 shows that there is weak dependence of the level of generated vibration and the wind direction.

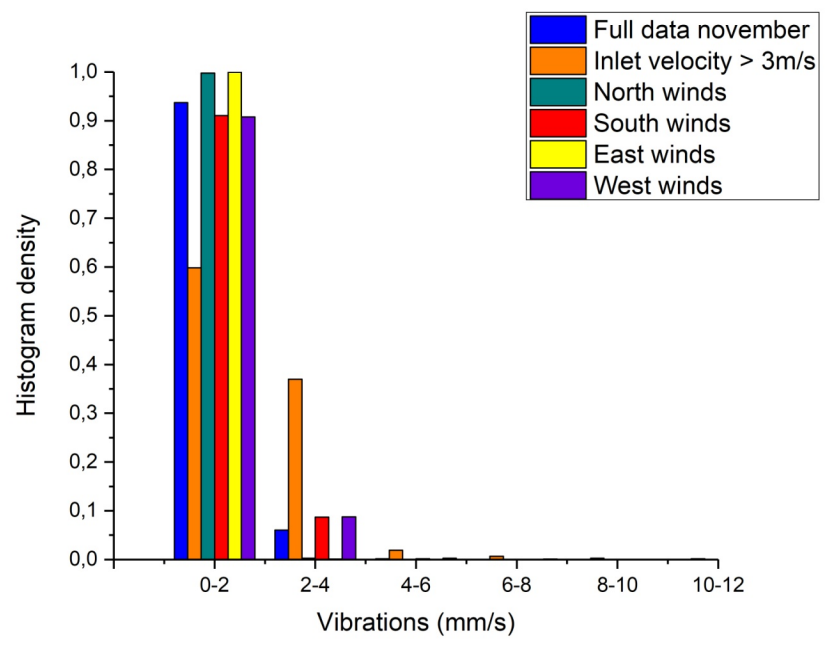

Fig. 9. Histograms of vibrations for varied wind directions. 
Low vibrations (in the range of $0-2 \mathrm{~mm} / \mathrm{s}$ ) are generated in a similar level independently of wind direction. The orange bar illustrates the effect of stronger winds (over $3 \mathrm{~m} / \mathrm{s}$ ) generating higher vibrations. However, vibrations in range of $2-4 \mathrm{~mm} / \mathrm{s}$ are generated mainly by west winds. Practically, there are no vibrations larger than $2 \mathrm{~mm} / \mathrm{s}$ generated by north wind. This is the effect of weaker winds from the N-E direction and specific placement of the turbine.

\section{Conclusions}

Ecological power generation in cities may play an important role in the future. An important share of power demand could be generated locally, without the necessity of transmission from other power plants. Small wind turbines can find their niches in this scenario. Most of locally generated energy can be used in case of an emergency, e.g. when blackouts occur. Energy stored in batteries can be used to supply critical building systems, e.g. communications, monitoring, etc.

The presented results show that for such a system, identification of wind conditions are very important. Turbine location near the building, at elevations, roofs, etc. practically do not interfere with the environment but may act on the building structure. Therefore, monitoring of noise and vibrations is treated seriously in the presented paper. Gathering of data may convince building users that properly installed small wind turbines do not create problems for exploitation of the building, moreover they can play a crucial role in unexpected situations delivering lacking energy.

This work was financially supported by the Statutory Grant of the Faculty of Energy and Fuels at AGH University of Science and Technology. The scientific infrastructure of the Center of Energy (Czarnowiejska 36, 30-054, Krakow, Poland, www.ce.agh.edu.pl) was used.

\section{References}

1. A. Yang, Y. Su, C. Wen, Y. Juan, W. Wang, C. Cheng, Appl Energ 171, 213-230 (2016)

2. M. Ragheb, Wind turbines in the urban environment (2012) www.energybc.ca/ cache/wind $/$ netfiles.uiuc.edu/mragheb/www/NPRE $\% 20475 \% 20$ Wind $\% 20$ Power $\% 20 \mathrm{~S}$ ystems/Wind\%20Turbines\%20in\%20the\%20Urban\%20Environment.pdf [access: 21.04.2018]

3. F. Toja-Silva, A. Colmenar-Santos, M. Castro-Gil, Renew Sust Energ Rev 24, 364-278 (2013)

4. A.R. Sengupta, A. Biswas, R. Gupta, ISESCO journal of science and technology 12, 11-16 (2017)

5. M. Haase, E. Lofstrom, Building augmented wind turbines, (BAWT, SINTEF Academic Press, 2015)

6. B.C. Cochran, R.R. Damiani, Harvesting wind power from tall buildings, (WINDPOWER 2008)

7. J. Park, H.J. Jung, S.W. Lee, J. Park, , Energies, 8, 11846-11870 (2015)

8. T.F. Ishugah, Y. Li, R.Z. Wang, J.K. Kiplagat, Renew Sust Energ Rev., 37, 613-626 (2014)

9. B. Grieser, Y. Sunak, R. Madlener, Renew Energ., 78, 334-350 (2015) 